\title{
Simulasi Direct Sequence Spread Spectrum (DSSS) Pada Modulasi Binary Phase Shift Keying (BPSK)
}

\author{
Faradila Alvina Putri ${ }^{1}$, Nabila Khansa Hartono ${ }^{2}$ dan Fitri Elvira Ananda ${ }^{3}$ \\ ${ }^{1,2,3}$ Program Studi Broadband Multimedia, Jurusan Teknik Elektro, Politeknik Negeri Jakarta \\ Jl. Prof. DR. G. A. Siwabessy, Kampus Baru UI, Beji, Depok, Jawa Barat, 16424, Indonesia. \\ E-mail:faradilaalvina03@gmail.com
}

\begin{abstract}
Abstrak
Spread spectrum adalah salah satu teknik pengiriman data yang menebarkan spektrum energi sinyal informasi dalam pita frekuensi yang jauh lebih besar dari spektrum minimal. Salah satu teknik spread spectrum adalah Direct Sequence Spread Spectrum (DSSS). Penelitian ini membuat rancangan simulasi DSSS pada modulasi Binary Phase Shift Keying (BPSK) dengan menggunakan software Matlab. Hasil perancangan yang ditampilkan pada simulasi DSSS ini adalah menampilkan gelombang sinyal informasi, PN code, sinyal yang sudah ditambahkan dengan PN code, sinyal yang dimodulasi dengan BPSK, sinyal modulasi yang sudah ditambahkan dengan noise AWGN, sinyal demodulasi, sinyal output DSSS serta grafik BER vs SNR pada kanal AWGN. Simulator DSSS pada penelitian ini sudah berjalan sesuai dengan alur proses DSSS pada BPSK secara teoritis.
\end{abstract}

Kata kunci: AWGN, BPSK, DSSS, PN Code, PN Sequence

\section{Abstract}

Spread spectrum is a data transmission technique that spreads out information spectrum energy signals in a frequency band that is much larger than the minimal spectrum. One of the spread spectrum techniques is Direct Sequence Spread Spectrum (DSSS). This research was built the simulation of DSSS on Binary Phase Shift Keying (BPSK) modulation using MATLAB software. The simulation results of this DSSS simulation are displaying information wave signals, $P N$ codes, signals that have been added with PN codes, signals modulated with BPSK, modulation signals that have been added with AWGN noise, demodulation signals, DSSS output signals and BER vS SNR graphics on the channel AWGN. The simulator of DSSS on BPKS in this research have been running according to the DSSS signal order flow and theoretical concept.

Keywords: AWGN, BPSK, DSSS, PN Code, PN Sequence

\section{Pendahuluan}

Dalam proses pengiriman data terdapat berbagai macam teknik yang digunakan untuk mendapatkan kualitas sinyal yang baik dan juga informasi yang sampai harus tahan terhadap gangguan. Pada zaman sekarang, dimana semua informasi dapat didapatkan dengan begitu mudah maka diharuskan untuk terus mengembangkan teknik pengiriman data di sisi transmisi agar keamanan informasi tetap terjaga. Salah satu teknik yang dapat diterapkan untuk mengatasi hal ini adalah teknik spread spectrum.
Spread spectrum adalah suatu teknik pengiriman sinyal informasi yang menggunakan suatu kode untuk menebarkan spektrum energi sinyal informasi dalam pita frekuensi yang jauh lebih besar dari spektrum minimal yang dibutuhkan untuk menyalurkan suatu informasi. Sistem komunikasi spread spectrum berguna untuk menekan adanya jamming. Konsep ini didasarkan pada teori C.E Shannon untuk kapasitas saluran [1] :

$$
C=W \log 2(1+S / N)
$$

Dimana :

$C=$ Kapasitas kanal transmisi $(b p s)$ 
$W=$ Lebar pita frekuensi transmisi $(\mathrm{Hz})$

$S=$ Daya sinyal (Watt)

$N=$ Daya noise $($ Watt $)$

Ada beberapa teknik modulasi yang dapat digunakan untuk menghasilkan spectrum sinyal tersebar [3] :

1. Direct Sequence, yaitu teknik modulasi dimana data digital dikodekan dengan bit-bit yang mempunyai kecepatan lebih tinggi dari kecepatan data. Kode bit-bit tersebut dibangkitkan secara random, kode bit tersebut juga digunakan pada sisi penerima untuk mendapatkan sinyal informasi seperti semula.

2. Frequency Hoping, yaitu teknik modulasi dimana data akan ditransmisikan pada frekuensi yang berbeda-beda atau berpindah-pindah (Hoping) dalam waktu yang cepat.

3. Hybrid, yaitu teknik modulasi gabungan antara direct sequence dan frequency hopping.

Direct Sequence Spread Spectrum (DSSS) memiliki data rate yang tinggi dan dikenal paling mudah implementasinya, oleh karena itu jenis spread spectrum ini paling banyak digunakan. DSSS ini menggunakan kode pseudo-noise yang berfungsi sebagai gelombang modulasi sinyal, lalu sinyal akan menyebarkan energi sinyalnya melalui bandwidth yang jauh lebih besar dari bandwidth sinyal informasi [2].

Pada sistem DSSS, pseudorandom sequence sangat berperan dalam proses spreading dan dispreading dari sinyal baseband. Pseudo noise (PN) atau pseudorandom sequence adalah biner sequence dengan autokorelasi yang mirip dalam satu periode. PN-code mempunyai satuan chips, yang merupakan sinyal pelebar informasi dan digunakan untuk membedakan antara kanal/pengguna satu dengan pengguna lain. Salah satu cara untuk menghasilkan sinyal PN adalah dengan menggunakan Maximum Length Sequences (MLS), yang menggunakan konsep polynomial seperti pada Gambar 1. Suatu MLS dibentuk dari gabungan shift register dan kumpulan sirkuit logic pada sistem feedback-nya, serta clock untuk mengatur periode pembangkitan chip pada deretan bit-bit sekuensi [2].

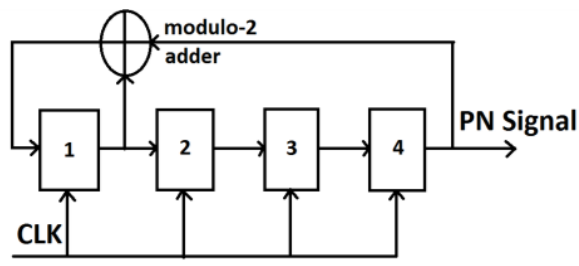

Gambar 1. Diagram blok PN sequence [3]
Teknik modulasi yang paling sering digunakan pada DSSS adalah Modulasi BPSK (Binary Phase Shift Keying). BPSK merupakan salah satu teknik modulasi digital yang bekerja dengan cara mengubah phasa frekuensi pembawa antara dua nilai yang menyatakan keadaan biner 1 dan 0 , dalam hal ini phasa dari frekuensi pembawa yang satu dengan yang lain berbeda sebesar $\pi$ radian atau $180^{\circ}$ [5]. Teknik modulasi digital dengan gelombang pembawa analog akan lebih meningkatkan kualitas Signal to Noise Ratio (SNR) jika dibanding dengan modulasi analog. Berikut ini rumus untuk SNR [3].

$$
\mathrm{SNR}=10 \log _{10}(\mathrm{~S} / \mathrm{N}) \mathrm{dB}
$$

Dimana :

$\mathrm{S}$ = Daya sinyal rata-rata (Watt)

$\mathrm{N}=$ Daya derau (Watt)

Additive White Gaussian Noise AWGN adalah gangguan yang bersifat additive pada saluran transmisi dan dimodelkan acak dalam distribusi Gaussian atau terdistribusi normal. Noise ini disebut white noise karena terdiri dari seluruh frekuensi dalam spektralnya sebagai cahaya putih atau memiliki rapat spektral daya yang konstan. White noise dihasilkan dalam simulasi dengan fungsi rand, sedangkan Gaussian noise dihasilkan dengan fungsi randn pada MATLAB. Setiap perhitungan komunikasi yang melalui kanal maka harus ditambahkan AWGN. Berikut formula pada kanal AWGN dan kapasitas C (b/s) dari sebuah kanal AWGN [4].

$$
\begin{gathered}
y=h x+n \\
C=B \log _{2}(1+S / N)
\end{gathered}
$$

Dimana:

$y=$ sinyal yang diterima

$x=$ sinyal yang dikirimkan

$h=$ kanal

$n=$ noise AWGN

$C=$ kapasitas $(\mathrm{b} / \mathrm{s})$

$B$ = bandwidth $(\mathrm{Hz})$

$S=$ Daya sinyal $($ Watt $)$

$N=$ Daya noise $(W a t t)$

Pada penelitian ini, dirancang simulasi pada salah satu teknik spread spectrum, yaitu DSSS menggunakan software MATLAB. Pada simulasi DSSS ini, digunakan salah satu modulasi digital yaitu Binary Phase Shift Keying (BPSK) sebagai modulator.

\section{Metode Penelitian}


Direct Sequence Spread Spectrum bekerja dengan menebarkan sinyal informasi dengan sinyal acak yang dihasilkan oleh pseudorandom. Sinyal informasi pada bagian pengirim mempunyai laju bit rendah, sedangkan sinyal pseudorandom memiliki laju bit jauh lebih tinggi dibandingkan sinyal informasi. Sehingga akan menghasilkan sinyal baru dengan lebar periode sinyal yang sama dengan pseudo noise. Kemudian sinyal tersebut dimodulasi terlebih dahulu sebelum dipancarkan melalui antena.

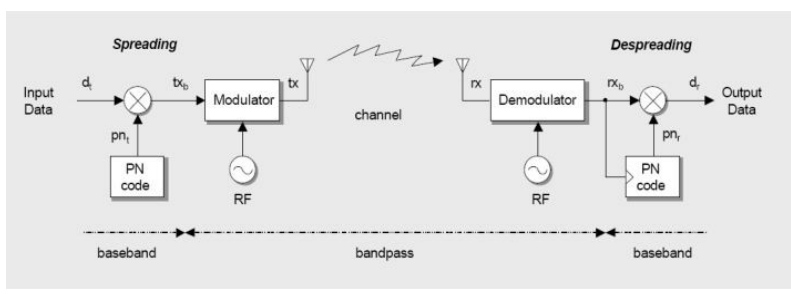

Gambar 2. Diagram blok Direct sequence spread spectrum [2]

Pada Gambar 2 dijelaskan alur pengiriman sinyal melalui proses DSSS. Input sinyal merupakan sinyal informasi sejumlah deret bilangan biner 8 bit. Pada proses spreading yang terjadi pada transmitter, data biner sinyal informasi pada bagian pengirim dikalikan dengan PN sequence. Efek dari perkalian tersebut merubah bandwidth sinyal $\mathrm{R}_{\mathrm{b}}$ menjadi bandwidth $\mathrm{R}_{\mathrm{c}}$. Selanjutnya pada proses despreading, sinyal spread spectrum tidak dapat langsung terdeteksi oleh penerima. Oleh karena itu, sinyal baseband yang diterima $\mathrm{rx}_{\mathrm{b}}$ dikalikan terlebih dahulu dengan $\mathrm{PN}$ sequence pada sisi penerima $\mathrm{pn}_{\mathrm{t}}$ sehingga nantinya pada output sinyal akan kembali seperti semula. Flowchart untuk proses DSSS seperti yang ditunjukkan oleh Gambar 3 dan untuk parameter yang digunakan pada simulasi ini di jelaskan pada Tabel 1.

Tabel 1. Parameter Sistem DSS yang Digunakan

\begin{tabular}{cc}
\hline Parameter & Spesifikasi \\
\hline Kode PN & 32 \\
Modulasi & BPSK \\
PN Sequence & 100 \\
Kanal & AWGN \\
SNR & $0-20 \mathrm{~dB}$ \\
\hline
\end{tabular}

Bit informasi yang dibangkitkan dikalikan dengan Pseudorandom (PN) sequence akan menghasilkan bit yang sudah di-spreading, sehingga menghasilkan sinyal baru yang mempunyai bit rate lebih kecil. Berikutnya dimodulasi dengan BPSK dan dilewatkan ke kanal AWGN. Pada sisi penerima, sinyal akan didemodulasi dan di-despreading, dari demodulasi akan dikalikan kembali dengan $\mathrm{PN}$ sequence yang sama dengan yang ada dalam proses spreading. Sehingga didapatkan kembali sinyal dengan bit rate seperti pada sinyal informasi awal. Pada simulasi ini, sinyal informasi, pseudorandom (PN) sequence, dan nilai SNR bersifat dinamis, artinya bit sinyal informasi dapat diubah sesuai user. Selain itu, pada simulasi DSSS ini diamati juga kinerja BER pada kanal AWGN

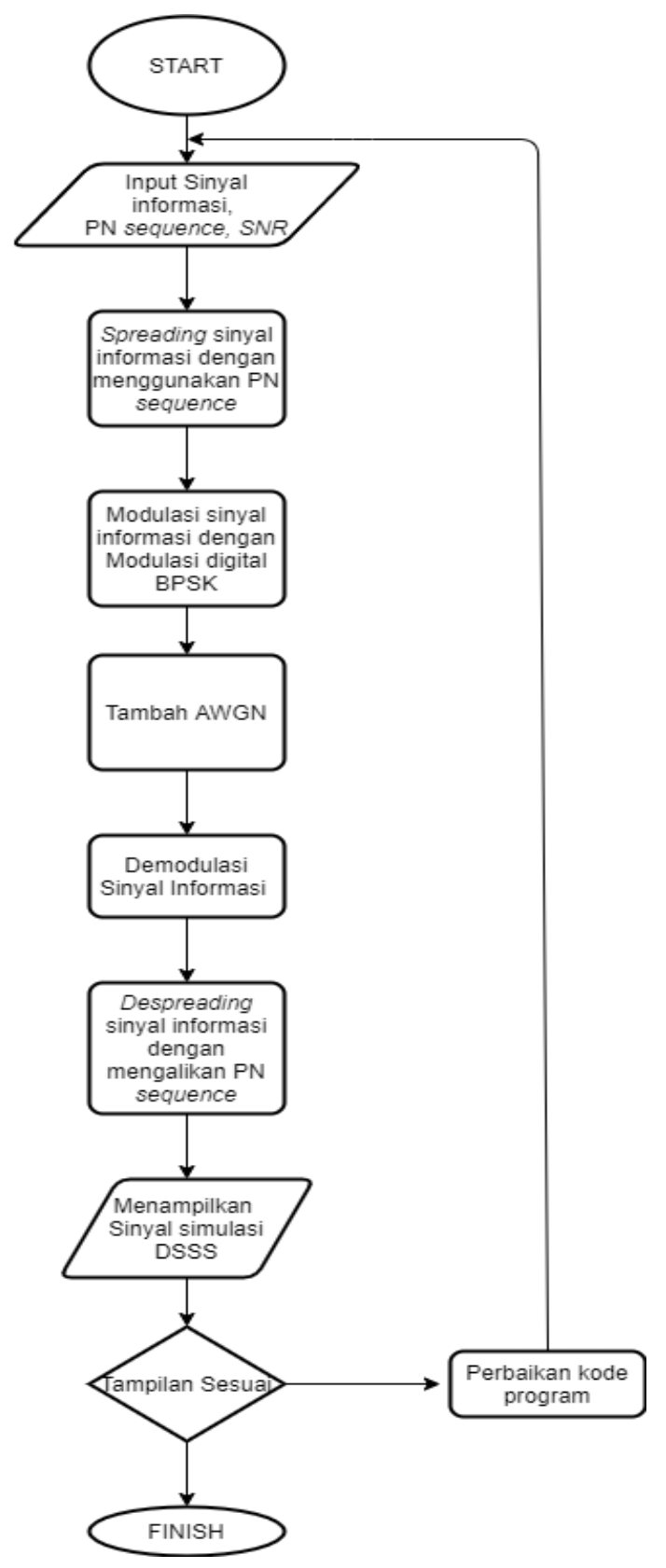

Gambar 3. Flowchart DSSS

\section{Hasil dan Pembahasan}


Pada simulasi DSSS ini, saat kode program sudah di-run maka tampilan pertama yang muncul adalah bagian untuk menginputkan bit informasi, PN sequence, dan nilai SNR yang akan disimulasikan hasilnya.

$\begin{array}{llllllll}\text { SpreadSpectrum } & \\ \text { Masukan input bit : }\left[\begin{array}{lllllllllll}0 & 0 & 1 & 1 & 1 & 1 & 0 & 0 & 0\end{array}\right]\end{array}$

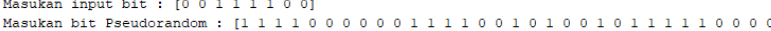
Masukkan nilai SNR : 20

Gambar 4. Input Bit Informasi, PN sequence dan Nilai SNR

Pada Gambar 4 terlihat bahwa sinyal informasi yang dimasukkan adalah $\left[\begin{array}{llllllll}0 & 0 & 1 & 1 & 1 & 1 & 0 & 0\end{array}\right]$ dan bit sebagai PN sequence adalah $\left[\begin{array}{lllllllllllllllll}1 & 1 & 1 & 1 & 0 & 0 & 0 & 0 & 0 & 0 & 1 & 1 & 1 & 1 & 0 & 0 & 1\end{array}\right.$ $\left.\begin{array}{lllllllllllllll}0 & 1 & 0 & 0 & 1 & 0 & 1 & 1 & 1 & 1 & 1 & 0 & 0 & 0 & 0\end{array}\right]$. Untuk nilai SNR dimasukkan nilai sebesar $20 \mathrm{~dB}$.
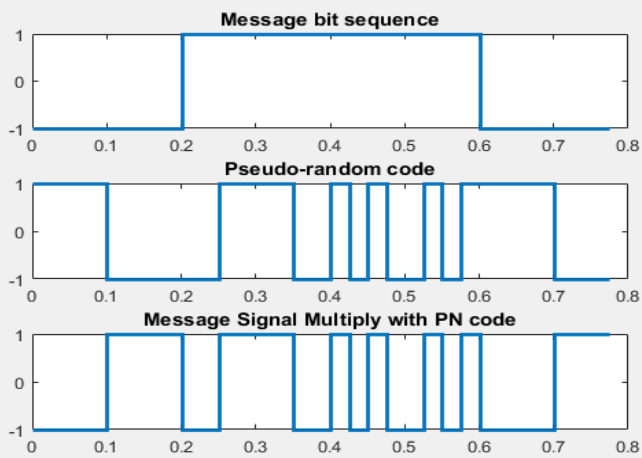

Gambar 5. Tampilan Sinyal Digital dari Sinyal Informasi, Sinyal PN Code, Gabungan Sinyal Informasi dan Sinyal PN Code

Pada Gambar 5 terlihat gambar sinyal informasi, PN code, dan sinyal informasi yang telah ditambahkan dengan PN code. Pada proses spreading DSSS menghasilkan sinyal XNOR dari penambahan sinyal informasi dengan PN code.

Gambar 6 menunjukkan tampilan sinyal modulasi dengan menggunakan BPSK dan sinyal yang telah diberi noise AWGN. Pada gambar pertama, sinyal yang dimodulasi digeser dengan fase isyarat pembawanya sebesar $\pi$ radian baik saat terjadi pergantian bit dari ' 0 ' ke ' 1 ' maupun sebaliknya. Pada gambar kedua memperlihatkan kinerja BER di kanal AWGN. Memperlihatkan bahwa bit terakhir pada sinyal modulasi BPSK terkena tambahan noise white gaussian.

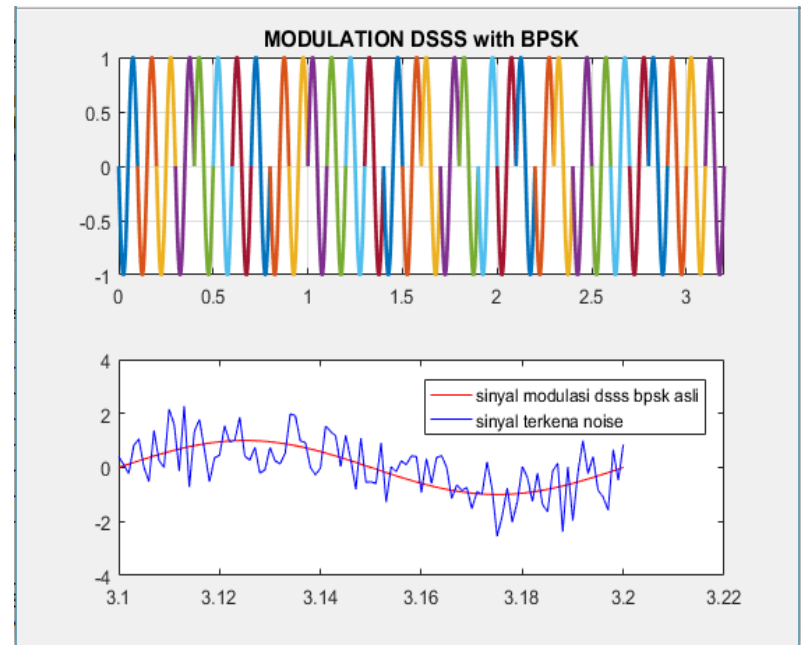

Gambar 6. Tampilan Sinyal Modulasi DSSS dengan BPSK dan Sinyal yang telah diberikan Noise AWGN
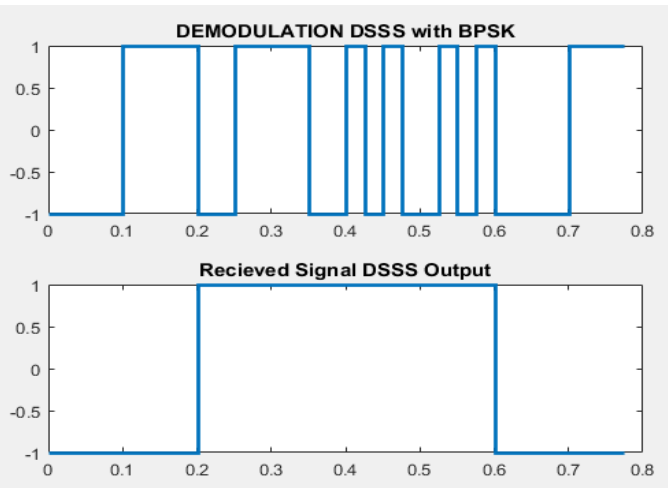

Gambar 7. Hasil Sinyal Output DSSS yang telah didemodulasi dan Sinyal yang Diterima Receiver

Pada Gambar 7 menampilkan sinyal DSSS yang telah didemodulasi pada gambar pertama dan sinyal output dari DSSS pada gambar kedua. Demodulasi adalah proses pengembalian sinyal ke bentuk sinyal sebelum dimodulasi. Oleh karena itu, demodulasi menghasilkan sinyal yang berbentuk seperti sinyal "Message Signal Multiply with PN Code" pada Gambar 6. Pada gambar kedua menghasilkan sinyal output DSSS. Sinyal ini merupakan sinyal informasi asli yang sebelumnya telah diuraikan oleh PN Code. Sinyal ini merupakan sinyal yang diterima pada receiver. 


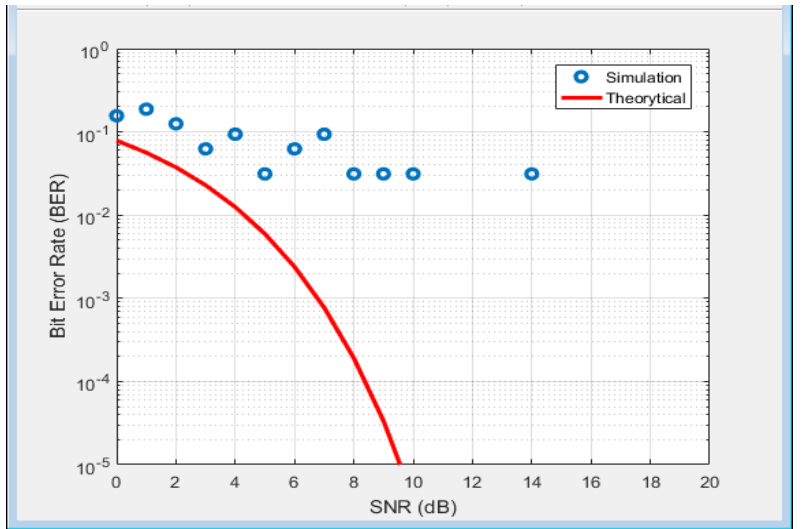

Gambar 8. Grafik BER vs SNR di kanal AWGN

Pada Gambar 8 menampilkan grafik BER VS SNR di kanal AWGN. Diperoleh hubungan antara fasa sinyal message signal multiply with pn_code terhadap SNR dan BER. Terlihat bahwa, level SNR yang semakin besar akan meingkatkan performansi sistem modulasi BPSK karena kesalahan menjadi semakin kecil atau nilai BER menjadi lebih rendah.

\section{Kesimpulan}

Spread spectrum digunakan untuk menyebarkan sinyal informasi melalui bandwidth yang lebih luas untuk mencegah adanya intercept (pencegatan), akibat spread spectrum hanya dapat dibaca oleh peralatan spread spectrum yang memiliki kode pseudo noise yang sama. Simulasi dilakukan menggunakan software MATLAB sudah berjalan sesuai dengan alur pembentukan sinyal DSSS pada BPSK secara teoritis. Hasil simulasi menampilkan sinyal informasi, sinyal PN code, sinyal informasi yang dikalikan dengan sinyal PN code, sinyal modulasi menggunakan teknik modulasi BPSK, lalu sinyal modulasi ditambahkan dengan noise AWGN, kemudian sinyal didemodulasi, lalu dikalikan dengan PN code untuk menampilkan sinyal output DSSS. Pada penelitian ini, hasil dari BER belum optimal diperkirakan akibat jumlah data informasi yang terbatas sehingga tidak cukup mewakili untuk mengamati tren kurva BER.

\section{Daftar Acuan}

[1] A.S. Putra, Suwadi, T. Suryani, Implementasi Dan Evaluasi Kinerja Direct Sequence Spread Spectrum Menggunakan Wireless Open-Access Research Platform (WARP). Institut Teknologi Sepuluh Nopember, Surabaya. 2015.

[2] N.A. Haryadi, Suwadi, T. Suryani. Implementasi Direct Sequence Spread Spectrum pada DSK TMS320C6416T, Jurnal Teknik POMITS Vol 3, No.1. Institut Teknologi Sepuluh Nopember, Surabaya. 2014.
[3] A.F. Isnawati, Diktat Komunikasi Data. Purwokerto: Akatel Sandhy Putra Purwokerto. 2006.

[4] Telkom University. 2015. AWGN (Additive White Gaussian Noise). https://miqbal.staff.telkomuniversity.ac.id/awgnadditive-white-gaussian-noise/ (diakses tanggal 04 Juli 2020).

[5] S. Kusmaryanto, Binary Phasa Shift Keying (BPSK). Universitas Brawijaya, Malang. 2004. 